\title{
Investigation of Optical, Structural and Electrical Properties of Heterostructure Fe203 Deposited by RF Magnetron Sputtering on ZnO Layer by Spray Pyrolysis
}

\section{Sevda Sarıtaş}

Ataturk University

Tuba Çakıcı ( $\sim$ tuba.cakici@atauni.edu.tr )

Atatürk University https://orcid.org/0000-0003-3130-996X

Günay Merhan Muğlu

Ataturk University: Ataturk Universitesi

Muhammet Yıldırım

Ataturk University: Ataturk Universitesi

\section{Research Article}

Keywords: Band gap energy, crystal structure, transmittance, morphology, polycrystalline

Posted Date: February 23rd, 2021

DOI: https://doi.org/10.21203/rs.3.rs-226703/v1

License: (c) (1) This work is licensed under a Creative Commons Attribution 4.0 International License.

Read Full License

Version of Record: A version of this preprint was published at Journal of Materials Science: Materials in Electronics on April 8th, 2022. See the published version at https://doi.org/10.1007/s10854-022-08100-4. 


\title{
Investigation of optical, structural and electrical properties of heterostructure
} $\mathrm{Fe}_{2} \mathrm{O}_{3}$ deposited by $\mathrm{RF}$ magnetron sputtering on $\mathrm{ZnO}$ layer by spray pyrolysis

\author{
Sevda Sarıtaşa , Tuba Çakıcı ${ }^{a^{*}}$, Günay Merhan Muğlu ${ }^{b}$, Muhammet Yıldırım ${ }^{c}$ \\ ${ }^{a}$ Department of Electrical and Energy Ispir Hamza Polat Vocational High School, Ataturk \\ University, 25250, Erzurum, Turkey \\ ${ }^{b}$ Department of Optician Hinis Vocational High School, Ataturk University, 25250, Erzurum, \\ Turkey \\ ${ }^{c}$ Department of Physics, Ataturk University, 25250, Erzurum, Turkey \\ *Corresponding author \\ E-mail address: tuba.cakici@atauni.edu.tr \\ Phone: +90-554-6988670, Fax: +90-442-4512985
}

\begin{abstract}
In this study, we, firstly, fabricated $\mathrm{Fe}_{2} \mathrm{O}_{3}$ thin film recently promising to be used in spintronic technology by magnetron sputtering technique on $\mathrm{ZnO}$ thin film prepared by spray pyrolysis at $450{ }^{\circ} \mathrm{C}$. The crystal structure, surface morphology and structure, chemical composition, optical and electronic properties, and electric properties of the $\mathrm{Fe}_{2} \mathrm{O}_{3} / \mathrm{ZnO}$ sample were performed by X-ray diffraction (XRD), scanning electron microscope (SEM) and atomic force microscope (AFM), energy-dispersive X-ray (EDX), ultraviolet-visible (UV-VIS) and Raman spectrometer, and Hall measurements, respectively. XRD measurements showed that $\mathrm{Fe}_{2} \mathrm{O}_{3}$ and $\mathrm{ZnO}$ thin films have monoclinic and hexagonal crystal structures, respectively, and also both of them are polycrystalline. SEM images proved that there is a very good with the stoichiometric formation of $\mathrm{ZnO}$ nanocrystals of spherical shape and demonstrate aggregation of the particles and AFM images displays the distribution of flake-like of $\mathrm{Fe}_{2} \mathrm{O}_{3}$ structure over the surface of $\mathrm{ZnO}$. UV-VIS and Raman measurements revealed that the $\mathrm{ZnO}$ and $\mathrm{Fe}_{2} \mathrm{O}_{3} / \mathrm{ZnO}$ heterostructure band's band gap energy are 3.277 and $3.24 \mathrm{eV}$, respectively. Finally, the calculated values of electric conductivity, $\sigma$, electron density, $\mathrm{n}$, and mobility of the electron, $\mu$, using the data obtained from Hall measurements are $4.39 \times 10^{2} \Omega^{-1} \cdot \mathrm{m}^{-1}, 6.88 \times 10^{21} \mathrm{~m}^{-3}$ and $3.99 \times 10^{-}$ ${ }^{1} \mathrm{~V}^{-1} \cdot \mathrm{m}^{2} . \mathrm{s}$, respectively.
\end{abstract}

Keywords: Band gap energy, crystal structure, transmittance, morphology, polycrystalline. 


\section{Introduction}

Especially last decades, multifunctional nanocrystalline thin films taking place among all magnetic materials and being a promising candidate besides the thin films used for a single application have great attention by the researchers due to their intriguing physical properties and potential applications in many fields [1]. One of the most studied these thin films are the magnetic thin films with multilayers with nanometer spacing, and they are the first metallic quantum structures which can be used in electronic devices such as reading heads in hard discs [2]. There is another type of thin film sample developed by a group in literature called magnetic/non-magnetic multilayers; they are known `spin valves' and are mostly used in magnetic storage devices [2].

Maghemite nanoparticles taking place among the magnetic materials are widely used in biomedical applications because their magnetism interacts easily with external fields, and they are also biocompatible and potentially non-toxic to humans $[3,4]$. In literature, there are other studies realised by two different groups. They have developed devices which can be used in the field of spintronics. Their studies have suggested that $\gamma-\mathrm{Fe}_{2} \mathrm{O}_{3}$ can be used as a magnetic tunnelling-barrier for room-temperature spin-filter devices $[5,6]$.

On the other hand, researchers have studied on the nanocomposites consisting of two or more metal oxide semiconductors, and they have developed thin film samples which can be used in photocatalysts [7], lithium batteries [8], solar cells [9], gas sensors [10], and spintronic applications [11]. Wang et al. have fabricated CdS/Fe3O4 and CdS/a-Fe2O3 heterostructures and investigated their magnetic, optical and photocatalytic properties [12]. Hong et al. have, first, fabricated $\mathrm{Fe} 3 \mathrm{O} 4 / \mathrm{ZnO}$ composite thin film and demonstrated that $\mathrm{Fe} 3 \mathrm{O} 4 / \mathrm{ZnO}$ 's photocatalytic activity is higher than $\mathrm{ZnO}$ [13].

Suryavanshi et al. ZnO is a wide band gap semiconductor (Eg. $\sim 3.37 \mathrm{eV})$, and the high efficiency of luminescence in the UV to have fabricated $\mathrm{Fe}_{2} \mathrm{O}_{3} / \mathrm{ZnO}$ structure onto fluorine-doped tin oxide (FTO) coated glass substrates. They have investigated the $\mathrm{ZnO}$ layer effect on their crystal structure, morphological, optical, and photocatalytic properties of the films [14]. In another study, Suryavanshi et al. have fabricated $\mathrm{Fe}_{2} \mathrm{O}_{3}$ and stratified $\mathrm{Fe}_{2} \mathrm{O}_{3} / \mathrm{ZnO}$ thin films applying chemical spray pyrolysis technique, and they have investigated their physicochemical properties in detail. They have also proven that $\mathrm{Fe}_{2} \mathrm{O}_{3} / \mathrm{ZnO}$ thin film prepared with $60 \mathrm{ml}$ quantity of $\mathrm{ZnO}$ solution has maximum 
photoelectrochemical performance and layered $\mathrm{Fe}_{2} \mathrm{O}_{3} / \mathrm{ZnO}$ thin films and $\mathrm{Fe}_{2} \mathrm{O}_{3}$ thin films have band gap energy values 2.65 and $2.10 \mathrm{eV}$, respectively [15].

$\mathrm{Fe}_{2} \mathrm{O}_{3}$ (iron oxide phases) thin film phases can involve devices with captivating magnetic, optical structure and semiconducting properties. After all, deposition of quality and satisfying iron oxide phase thin films is quite tricky and requires vacuum processes. [16].

In this study, we have, first, formed $\mathrm{ZnO}$ thin film onto glass substrates by chemical pyrolysis, and then $\mathrm{Fe}_{2} \mathrm{O}_{3}$ nanocrystalline thin films have been grown on them by RF sputtering technique. The characteristics of the $\mathrm{Fe}_{2} \mathrm{O}_{3} / \mathrm{ZnO}$ structures were carried out by XRD, Raman Spectroscopy, FE-SEM with EDX, AFM and UV-Vis spectrophotometer techniques.

The present work aims to study the optical, structural, and electrical properties of $\mathrm{Fe}_{2} \mathrm{O}_{3} / \mathrm{ZnO}$ heterostructure. Firstly, it has been revealed that the hardly growing $\mathrm{Fe}_{2} \mathrm{O}_{3}$ phase in iron oxides grow on another film at the nanoscale.

\section{Experimental}

In this our study, we have realised the fabrication of $\mathrm{Fe}_{2} \mathrm{O}_{3} / \mathrm{ZnO}$ structure in two stages as follows: we have, first, formed $\mathrm{ZnO}$ thin film onto a glass substrate by spray pyrolysis method, and then we have formed $\mathrm{Fe}_{2} \mathrm{O}_{3}$ thin film over it by RF magnetron sputtering technique to obtain $\mathrm{Fe}_{2} \mathrm{O}_{3} / \mathrm{ZnO}$ structure.

\subsection{Formation $\mathrm{ZnO}$ thin film onto the glass substrate}

In the first step, we used the methenamine $\left(\mathrm{CH}_{2}\right)_{6} \mathrm{~N}_{4}$ salt powders (Merck and with purity 99.9\%) and zinc nitrate hexahydrate $\left(\mathrm{Zn}\left(\mathrm{NO}_{3}\right)_{2} \cdot 6 \mathrm{H}_{2} \mathrm{O}\right)$ as precursor materials forming the $\mathrm{ZnO}$ thin film sample onto the glass substrate. To do it, we have weighed 1.486 gr of $\mathrm{Zn}\left(\mathrm{NO}_{3}\right)_{2} \cdot 6 \mathrm{H}_{2} \mathrm{O}$ and $0.7 \mathrm{gr}$ of $\left(\mathrm{CH}_{2}\right) 6 \mathrm{~N}_{4}$ salts in powders and put each of them into two separate glass beakers filled $50 \mathrm{ml}$ deionised water. And then we obtained two solutions stirring these two mixtures for 40 minutes by a magnetic mixer. Then, we poured these two solutions into another glass beaker and stirring this solution with the magnetic mixer 
we have obtained the final solution of $100 \mathrm{ml}$ which will be used in the deposition of $\mathrm{ZnO}$ thin film samples. We loaded this solution into the syringe. After these processes, we have passed for the deposition of the $\mathrm{ZnO}$ thin film samples. Firstly, we have placed the ten substrates with $1 \times 1 \mathrm{~cm}^{2}$ that we prepared from microscope glasses and cleaned applying a known cleaning method Piranha [17] on the heater plate in chemical pyrolysis experimental-set and heated the heater plate until $450{ }^{\circ} \mathrm{C}$. Finally, we adjusted the pump to pump the solution through the nozzle with a solution's flow rate of $2.5 \mathrm{ml} / \mathrm{min}$. We have then started the pump to spray the solution on the substrates and obtained 10 number of $\mathrm{ZnO}$ thin film samples. Then we divided these 10 number of thin film samples into two groups, each group including five thin film samples. We have used one of these group samples to characterize $\mathrm{ZnO}$ thin film samples and the other group for the fabrication of the $\mathrm{Fe}_{2} \mathrm{O}_{3}$ layer on $\mathrm{ZnO}$.

\subsection{Formation of $\mathrm{Fe}_{2} \mathrm{O}_{3} / \mathrm{ZnO}$ heterostructure}

After completing the above processes, we started the second step. We placed $\mathrm{Fe}_{2} \mathrm{O}_{3}$ thin films with 2-inch radius prepared by us and $\mathrm{ZnO}$ thin film samples on the $\mathrm{RF}$ magnetron sputtering system's anode and cathode plates, respectively. We then adjusted the pressure inside the system and controlled the flow rates of argon and oxygen gases $\left(\mathrm{O}_{2} / \mathrm{Ar}=1 / 14\right)$ total combustion chamber of the system $1.4 \times 10^{-6}$ Torr 25 mTorr, respectively. Oxygen partial pressure during the growing of the $\mathrm{Fe}_{2} \mathrm{O}_{3}$ layer on $\mathrm{ZnO}$ thin film substrates was accepted as the fundamental parameter for determining the samples' optical and structural properties. After adjusting the power supply, the substrates' temperature, and taking the distance the target (source material) and substrates as $100 \mathrm{~W}, 290^{\circ} \mathrm{C}$, and $4.5 \mathrm{~cm}$, we started the system and fabricated the $\mathrm{Fe}_{2} \mathrm{O}_{3} / \mathrm{ZnO}$ thin film samples.

Finally, completing the production of the heterostructures, we performed the characterisation of heterostructure samples.

Crystal structure- crystal energy bond structure, surface morphology, qualitative analysis, and optical properties of $\mathrm{Fe}_{2} \mathrm{O}_{3}$ heterostructure samples were examined by using X-ray diffractometer (XRD Bruker D2, $\mathrm{K} \alpha, \lambda=1.54$ A, Scanning angle 70o], Raman Spectroscopy (WITec alpha 300 Series Raman High-Resolution Optical and Scanning 
Probe Microscopy Systems measurements), scanning electron (FE-SEM) (Sigma 300 Model Zeiss Gemini) and atomic force microscope (AFM) (AFM 5000 II Model), Electron diffusion x-ray (EDX associated with FE-SEM) and UV-VIS spectrometer (Perkin-Elmer Lambda 2S UV-Visible spectrometer) techniques, respectively. Also, electronic properties of $\mathrm{Fe}_{2} \mathrm{O}_{3}$ heterostructure samples were examined by Hall measurement method.

\section{Results and Discussion}

\subsection{XRD and Raman measurements}

Fig. 1 shows the XRD measurements of the $\mathrm{ZnO}$-pure (black line) and $\mathrm{Fe}_{2} \mathrm{O}_{3} / \mathrm{ZnO}$ heterostructure (red line) thin film samples. As seen from Fig.1, peaks belonging to ZnOpure thin film appear at the angles 32.00, 35.00, 38.00, 48.49, 57.56, 63.72, and 68.82 degrees corresponding to (100), (002), (101), (102), (110), (103), and (112) the (h,k,l) diffraction planes, respectively. Therefore, $\mathrm{ZnO}$-pure thin film sample has a hexagonal crystal structure [18] and a polycrystalline structure. This result was identified and matched well with the PDF No: 01-075-1533 pattern corresponding to ZnO's hexagonal crystal phase. On the other hand, the peaks in XRD patterns of $\mathrm{Fe}_{2} \mathrm{O}_{3} / \mathrm{ZnO}$ thin films (This measurement was performed applying Grazing Incidence XRD (GIXRD)) appear at three angles $32.73,35.43$, and 36.50 degrees corresponding to (402), (040), and (200) the $(h, k, l)$ diffraction planes, respectively. The first two peaks correspond to $\mathrm{Fe}_{2} \mathrm{O}_{3}$ crystallisation, and the third one shows the $\mathrm{ZnO}_{2}$ crystallites, and these results were clearly identified and match well with the PDF No: 00-013-0311 pattern corresponding to a monoclinic $\mathrm{Fe}_{2} \mathrm{O}_{3}$ (Maghemite) structure and cubic crystal phase of $\mathrm{ZnO}_{2}$, respectively. The rest of the peaks correspond to the $\mathrm{ZnO}$-pure thin film.

The $\mathrm{ZnO}_{2}$ crystallites emerge during the growth process of the $\mathrm{Fe}_{2} \mathrm{O}_{3}$ on $\mathrm{ZnO}$ thin film substrate employing $\mathrm{Rf}$ magnetron sputter resulting from the $\mathrm{O}_{2}$ gas being still inside the 
chamber. During this process, $\mathrm{O}_{2}$ gas molecules are adsorbed on $\mathrm{ZnO}$ thin film, and hence cubic $\mathrm{ZnO}_{2}$ phase is formed along the (200) plane. On the other hand, we calculated the crystal sizes of the thin film samples corresponding to the angles that the peaks appear using the Debye-Scherrer formula,

$$
D=\frac{0,9 \lambda}{\beta \cos \theta}
$$

herein, $\Theta$ the corresponding Bragg's angle, $\beta$ is the full width at half maximum (FWHM), $\beta$ is the full width at half maximum (FWHM) of XRD peak, and $\lambda$ is the wavelength of the incident X-ray $(\lambda=1.5405 \AA)$.

Crystal structure parameters of the heterostructure thin film sample are given in Table 1. The calculated values of both of these two thin film samples' crystal sizes confirm that they also have a polycrystalline structure with different sizes.

Raman spectrum is the primary method to characterise the materials bond structure. Electron-phonon interaction has a significant effect on the electronic and optical structure of the materials. Raman spectra give information about materials' energy relaxation rate of excited carriers and phonon reproduction of excitons in the luminescence [19]. Therefore, we used Raman scattering technique on the fabricated $\mathrm{Fe}_{2} \mathrm{O}_{3} / \mathrm{ZnO}$ thin film sample since this technique is more sensitive to crystallisation, structural disorder and defects in nanocrystalline thin films some of the other techniques. In Fig. 2, the roomtemperature Raman spectra at the range of $0-3500 \mathrm{~cm}^{-1}$ for the heterostructure $\mathrm{Fe}_{2} \mathrm{O}_{3} / \mathrm{ZnO}$ and $\mathrm{ZnO}$ thin film samples are given with the graphics blue-black, respectively. As seen from Fig.2, while the first typical Raman peak of $\mathrm{ZnO}$ thin film is seen at $95 \mathrm{~cm}^{-1}$, it is seen that this peak shifts to $98 \mathrm{~cm}^{-1}$ for $\mathrm{Fe}_{2} \mathrm{O}_{3} / \mathrm{ZnO}$ structure. On the other hand, the intensity of the peak corresponding to $\mathrm{ZnO}$ thin film observed at $434 \mathrm{~cm}^{-1}$ 
decreases. Also, the typical Raman peak of $\mathrm{Fe}_{2} \mathrm{O}_{3} / \mathrm{ZnO}$ is observed at $573 \mathrm{~cm}^{-1}$. The peaks appearing in the Raman spectrum of $\mathrm{ZnO}$ at 1105 and $1448 \mathrm{~cm}^{-1}$ shift toward 1108 and $1451 \mathrm{~cm}^{-1}$ in the $\mathrm{Fe}_{2} \mathrm{O}_{3} / \mathrm{ZnO}$ structure. The reason causing these changes can be attributed to the oxygen vacancies and crystal defects formations during the deposition of $\mathrm{Fe}_{2} \mathrm{O}_{3}$ layer on the $\mathrm{ZnO}$ layer by magnetron sputtering.

\subsection{FE-SEM (with EDX) and AFM measurements}

The thin film surface morphology of the prepared sample was revealed from the AFM and FE-SEM analysis techniques. Fig. 3 (a), (b) and (c) display FE-SEM micrographs of $\mathrm{ZnO}$ thin film sample, $\mathrm{Fe}_{2} \mathrm{O}_{3} / \mathrm{ZnO}$ heterostructure thin film, and magnified FE-SEM image of $\mathrm{Fe}_{2} \mathrm{O}_{3} / \mathrm{ZnO}$ structure grown on the glass substrate. Fig. 3 (a) shows that $\mathrm{ZnO}$ FE-SEM micrograph exhibits three-dimensional (3D) flower-like structures with nanometer-scale and also this FE-SEM image shows there is a very good with Stoichiometric formation of $\mathrm{ZnO}$ nanocrystals of spherical shape and prove to gather of the particles. This gathering results from the thermal heat reaction during the fabrication of the thin film fabrication and the dispersal of the crystallites are well-ordered and congenerous structure. This result is confirmed in the literature [20-21].

In Fig. 3b displays the distribution of flake-like of $\mathrm{Fe}_{2} \mathrm{O}_{3}$ structure over the subsurface area of $\mathrm{ZnO}$ thin film with granular morphology and the surface area of the thin film have no pinholes. These nanosheets are seen as the sheets distributed into $\mathrm{ZnO} 3 \mathrm{D}$ flower-like structures. Fig. (3c) displays the morphology of $\mathrm{Fe}_{2} \mathrm{O}_{3} / \mathrm{ZnO}$ structure seen in Fig. 3 (b) with different FE-SEM images' magnification rate. In this Fig., the distribution of flakelike $\mathrm{Fe}_{2} \mathrm{O}_{3}$ is seen more clearly over the $\mathrm{ZnO}$ thin film. 
Nanosheets originate from the ingredients $\mathrm{Fe}_{2} \mathrm{O}_{3}$ nanoscale thin film grown on $\mathrm{ZnO}$ thin film by sputtering technique ( $\mathrm{Rf}$ magnetron sputtering). Therefore, these $\mathrm{Fe}_{2} \mathrm{O}_{3}$ should appear on the $\mathrm{ZnO}$ thin film as nanosheets with nanoscale.

FE-SEM is appointed with an EDX analysis system to make compositional analysis on material localisation surface area. The typical EDX spectrum demonstrates in Fig. 4 indicates the composition instructions on components in the $\mathrm{Fe}_{2} \mathrm{O}_{3} / \mathrm{ZnO}$ heterostructure. As seen from Fig.4, the components accruing in the combination of $\mathrm{Fe}_{2} \mathrm{O}_{3} / \mathrm{ZnO}$ heterostructure and their component rates procured from EDX measurements are shown in the list. $\mathrm{Fe}_{2} \mathrm{O}_{3} / \mathrm{ZnO}$ heterostructure sample elements have consisted of $\mathrm{O}, \mathrm{Fe}, \mathrm{Zn}, \mathrm{Au}$ and $\mathrm{Si}$ elements. Elements like $\mathrm{O}, \mathrm{Fe}$, and $\mathrm{Zn}$ are the elements to take place in the $\mathrm{Fe}_{2} \mathrm{O}_{3} / \mathrm{ZnO}$ heterostructure sample composition. However, the nominal rate of $\mathrm{Au}$ and $\mathrm{Si}$ elements are existent in the composition of this thin film sample. It is considered that $\mathrm{Si}$ element comes from the glass substrate and the presence of Au element take its source from $\mathrm{Au}$ used to overlay the surface of $\mathrm{Fe}_{2} \mathrm{O}_{3} / \mathrm{ZnO}$ sample before the FE-SEM measurement.

Fig. 5 (a) and (b) display the 3D and 2D RMS (459 nm) AFM micrograph image of the $\mathrm{Fe}_{2} \mathrm{O}_{3} / \mathrm{ZnO}$ heterostructure, respectively. The surface roughness plays a vital role in the transportation of charge in thin films and determines any inter surface layer thin film device application features. It is seen from Fig.5 (a) that AFM topographic reveals that there is a smooth distribution of $\mathrm{ZnO}$ crystallites forming the first layer and the flake type $\mathrm{Fe}_{2} \mathrm{O}_{3}$ crystallites distributed at a less density over it. This result is also confirmed by the XRD and FE-SEM measurements. Additionally, the mean roughness of the $\mathrm{Fe}_{2} \mathrm{O}_{3} / \mathrm{ZnO}$ sample was found at $459 \mathrm{~nm}$. As a result, it can be said that the fabricated $\mathrm{Fe}_{2} \mathrm{O}_{3} / \mathrm{ZnO}$ 
heterostructure thin film sample has a highly smooth and almost uniform surface structure.

\subsection{Optical properties}

Optical absorption spectra of $\mathrm{ZnO}$-pure and $\mathrm{Fe} 2 \mathrm{O} 3 / \mathrm{ZnO}$ heterostructure thin film samples are given in Fig.6 at the range of between 300 and 900 nm. It is seen from Fig.6 that absorption of the light is robust for these two samples in the UV range. The optical band gap of thin film materials can be calculated using absorption data, which is generally a well-known method. Optical band gap energy values of these thin film samples are calculated from their absorption data.

To calculate the absorption coefficient (a) using the expression;

$$
I=I_{0} e^{-a d}
$$

where I and $\mathrm{I}_{0}$ transmitted are and incident photon radiation intensities, respectively. The thickness of the film is d. The optical band gap energy $\left(E_{g}\right)$ values are ascertained from the equation:

$$
a h v=A\left(h v-E_{g}\right)^{n}
$$

herein, $\mathrm{E}_{\mathrm{g}}$ is the band gap energy, $h v$ is the energy of the photon, $\mathrm{h}$ is the Planck constant A is a constant reason to the effective masses of charge carriers, and $n$ is the power based on the optical transition character $(\mathrm{n}=0.5$ and 2 for direct and indirect transition, respectively) [22]. After calculating the $\alpha \mathrm{i}$ 's, implantation these values and the values of the other characteristic parameters displayed in Equ.2, they are plotted the graphics of $(\mathrm{ahv})^{2}$ versus hv for $\mathrm{ZnO}$-pure and $\mathrm{Fe}_{2} \mathrm{O}_{3} / \mathrm{ZnO}$ heterostructure thin film samples (Fig. 7). It is applied the extrapolation way to determine the band gap energy, $\mathrm{E}_{\mathrm{g}}$, of $\mathrm{ZnO}$-pure thin film and $\mathrm{Fe}_{2} \mathrm{O}_{3} / \mathrm{ZnO}$ heterostructure. According to this way, the slope at the intersection of the photon energy at the point where the absorption is zero gives the band gap energy 
value. As seen from Fig.7, the intercepts corresponding to the band gap energy of $\mathrm{ZnO}$ pure thin film and $\mathrm{Fe}_{2} \mathrm{O}_{3} / \mathrm{ZnO}$ structure are $3.277 \mathrm{eV}$ and $3.24 \mathrm{eV}$, respectively. Due to doping and ensuing defect, the band structure and absorption edges change [23]. Significantly, the drop in the band gap with the $\mathrm{Fe}_{2} \mathrm{O}_{3}$ deposition another layer on $\mathrm{ZnO}$ could be assumed as the inlet of oxygen and iron energy states in the top of the valence band.

\subsection{Hall measurements}

Electrical and magnetic characteristics parameter of the $\mathrm{Fe}_{2} \mathrm{O}_{3} / \mathrm{ZnO}$ thin film sample was performed by using full automation cryogenic hall measuring system whose schematic diagram presenting its operation principle (Fig.8). As seen from Fig.8, the thin film sample is placed in a magnetic field produced by the experimental set-up and the Hall voltage, $\mathrm{V}_{\mathrm{H}}$, and the current passing through the sample in the $\mathrm{x}$-direction, $\mathrm{I}_{\mathrm{x}}$, is measured by the system. So, we entered the value of magnetic field $B_{z}(2.5 T)$, and the width, $w$ $(0.5 \mathrm{~cm})$, length, $\mathrm{L}(1.5 \mathrm{~cm})$, and thickness $(600 \mathrm{~nm})$ of the sample as input and started the experimental set-up to operate. The numerical values of the Hall coefficient, $\left(R_{H}\right)$, carrier density (n), resistivity $(\rho)$, conductivity $(\sigma)$, hall mobility, $\mu_{H}$, and also magnetoresistance coefficient, $\mathrm{MR}_{\mathrm{c}}$, of the for $\mathrm{Fe}_{2} \mathrm{O}_{3} / \mathrm{ZnO}$ sample were calculated by a computer program using the $\mathrm{B}$ value and the measured values of $\mathrm{V}_{\mathrm{H}}$ and

$I_{x}$ values are given in Table 2 in the following equations:

Substituting the measured values of $\mathrm{V}_{\mathrm{H}}(0.455 \mathrm{~V})$ and $\mathrm{I}_{\mathrm{x}}\left(1.2 \times 10^{-4} \mathrm{~A}\right)$ and given values of $\mathrm{B}(2.5 \mathrm{~T})$ and thickness of the thin film, $\mathrm{t}(600 \mathrm{~nm})$ in the equation,

$$
R_{H}=\frac{V_{H} t}{I_{x} B}
$$

The calculated value of $\mathrm{R}_{\mathrm{H}}$ is $9.1 \times 10^{-4} \mathrm{~m}^{3} /$ A.s. Elektron's density 
is obtained substituting the value of e $\left(1.6 \times 10^{-19} \mathrm{C}\right)$ and the value of $\mathrm{R}_{\mathrm{H}}$ calculated as above in the following equation,

$$
n=\frac{1}{e R_{H}}
$$

The obtained value for $\mathrm{n}$ is $6.88 \times 10^{21} \mathrm{~m}^{-3}$. The conductivity of the sample, $\sigma$, is calculated using the following equation,

$$
\sigma=\frac{\mathrm{I}_{\mathrm{x}}}{\mathrm{V}_{\mathrm{H}} \mathrm{t}}
$$

Furthermore, the calculated value of the conductivity of the sample is $4.39 \times 10^{2} \Omega^{-1} \cdot \mathrm{m}^{-1}$. Substituting the values of $R_{H}$ and $\sigma$ in the following equation, we find the value of mobility of the sample,

$$
\mu_{n}=-R_{H} \sigma
$$

it is obtained as $3.99 \times 10^{-1} \mathrm{~V}^{-1} \cdot \mathrm{m}^{2} . \mathrm{s}$. The obtained values of these parameters are the expected values, and they are in a good agreement with the results obtained from the studies in the literature [24-27].

\section{Conclusion}

Firstly, with this study, it has been realized that $\mathrm{Fe}_{2} \mathrm{O}_{3}$ thin film could be formed by magnetron sputtering technique on $\mathrm{ZnO}$ thin film produced by spray pyrolysis method successfully. XRD, Raman Analysis, FE-SEM, EDX and AFM studies show ZnO and $\mathrm{Fe}_{2} \mathrm{O}_{3}$ structures in the prepared $\mathrm{Fe}_{2} \mathrm{O}_{3} / \mathrm{ZnO}$ structure. Especially, FE-SEM analysis revealed that $\mathrm{Fe}_{2} \mathrm{O}_{3}$ nanosheets are constructed in 3D flake-like $\mathrm{ZnO}$ structure. These $\mathrm{Fe}_{2} \mathrm{O}_{3}$ nanosheets are observed in AFM images, and FE-SEM analysis results confirm this result.

Electrical properties of $\mathrm{Fe}_{2} \mathrm{O}_{3} / \mathrm{ZnO}$ structure has been investigated by using galvanomagnetic measurements. So by using the four-point method in Hall experiment, Hall coefficient, carrier density $(n)$, resistivity $(\rho)$, conductivity $(\sigma)$, hall mobility $(\mu)$ and also magnetoresistance coefficient (MR.Coeff.) have been determined for $\mathrm{Fe}_{2} \mathrm{O}_{3} / \mathrm{ZnO}$ 
structure. Due to the positive $\mathrm{R}_{\mathrm{H}}(=7,99 \mathrm{E}-01)$ value, $\mathrm{Fe}_{2} \mathrm{O}_{3} / \mathrm{ZnO}$ structure exhibits p-type electrical properties. Finally, these obtained results have shown that this fabricated thin film sample can be an excellent promising candidate to be used in spintronic applications.

\section{Acknowledgement}

The authors would like to thank Prof. Dr Refik Kayali (Omer Halis Demir University, Turkey) for his generous support for full-text reduction.

\section{References}

[1] A. Roychowdhury, S.P. Pati, A.K. Mishra, S. Kumar and D. Dast, Magnetically addressable fluorescent $\mathrm{Fe}_{3} \mathrm{O}_{4} / \mathrm{ZnO}$ nanocomposites: Structural, optical and magnetisation studies, J. of Phys. and Chem. of Solids., 2013, 74, p 811-818.

[2] F. J. Himpsel, J. E. Ortega, G. J. Mankey and R. F. Willis, Magnetic Nanostructure, Adv. Phys., 1998, 47 (4) p 511- 597.

[3] Q.A. Pankhurst, J. Connolly, S.K. Jones, and J. Dobson, Applications of magnetic nanoparticles in biomedicine, J. Phys. D.-Appl. Phys., 2003, 36, p R167.

[4] M. Levy, C. Wilhelm, J.M. Siaugue, O. Horner, J.C. Bacri, and F. Gazeau, Magnetically induced hyperthermia:size-dependent heating power of $\gamma$-Fe2O3 nanoparticles, J. Phys.: Condens. Matter, 2008, 20, 204133 (5pp)

[5] J.A. Wiemann, E.E. Carpenter, J. Wiggings, W. Zhou, J. Tang, S. Li, V. John, G. J. Long and A. Mohan, Magnetoresistance of a $\left(\gamma-\mathrm{Fe}_{2} \mathrm{O}_{3}\right) 80 \mathrm{Ag} 20$ nanocomposite prepared in reverse miçelle, J. Appl. Phys., 2000, 87, p 7001.

[6] H. Yanagihara, M. Hasegawa, E. Kita, Y. Wakabayashi, H. Sawa, and K. Siratori, Iron Vacancy Ordered $\gamma-\mathrm{Fe}_{2} \mathrm{O}_{3}(001)$ Epitaxial Films: The Crystal Structure and Electrical Resistivity, J. Phys. Soc. Jap, 2006, 75, p 054708.

[7] G. Williams, B. Seger, P.V. Kamat, TiO2-Graphene Nanocomposites. UV-Assisted Photocatalytic Reduction of Graphene Oxide, ACS Nano, 2008, 2(7), p 1487-1491. 
[8] J. Yan, X. Shen, B. Wang, and G. Wang, In situ chemical synthesis of SnO2-graphene nanocomposite as anode materials for lithium-ion batteries Electrochem. Commun., 2009, 11(10), p 1849- 1852.

[9] H. Xu, C. Zhang, Z. Wang, S. Pang, X. Zhou, Z. Zhang, and G. Cui Nitrogen-doped carbon and iron carbide nanocomposites as cost-effective counter electrodes of dyesensitised solar cells, J. Mater. Chem. A, 2014, 2(13), p 4676-4681.

[10] G. Sun, H. Chen, Y. Li, Z. Chen, S. Zhang, G. Ma, T. Jia, J. Cao, H. Bala, X. Wang, and Z. Zhang, Synthesis and improved gas sensing properties of NiO-decorated SnO2 micro flowers assembled with porous nanorods, Sens. Actuators, B Chem., 2016, 233, p 180-192.

[11] P. Sandhya Rani, R.Singh, Electron spin resonance and magnetisation studies of ZnO-TeO2-Fe2O3 glasses, Journal of Physics and Chemistry of Solids, 2013, 74, p $338-343$.

[12] L. Wang, H. Wei, Y. Fan, X. Gu, J. Zhan, One-dimensional CdS $/ \alpha-\mathrm{Fe}_{2} \mathrm{O}_{3}$ and $\mathrm{CdS} / \mathrm{Fe}_{3} \mathrm{O}_{4}$ heterostructures: epitaxial and non-epitaxial growth and photocatalytic activity, J. Phys. Chem. C, 2009, 113, p 14119.

[13] R.Y. Hong, S.Z. Zhang, G.Q. Di, HZ Li, Y. Zheng, J. Ding and D.G. Wei, Preparation, characterisation and application of $\mathrm{Fe}_{3} \mathrm{O}_{4} / \mathrm{ZnO}$ core/shell magnetic nanoparticles, Mater. Res. Bull., 2008, 43, p 2457.

[14] R.D. Suryavanshi, S.V. Mohite, A. A. Bagade, K. Y. Rajpure, Photoelectrocatalytic activity of spray deposited $\mathrm{Fe}_{2} \mathrm{O}_{3} / \mathrm{ZnO}$ photoelectrode for degradation of salicylic acid and methyl orange dye under solar radiation, Materials Science and Engineering: B, 2019, 248, p114386. https://doi.org/10.1016/j.mseb.2019.114386

[15] R. D. Suryavanshi, K. Y. Rajpure, Spray deposited $\mathrm{Fe}_{2} \mathrm{O}_{3}$ and stratified $\mathrm{Fe}_{2} \mathrm{O}_{3} / \mathrm{ZnO}$ novel photoelectrode photo-electrocatalytic degradation of benzoic acid 
under solar light illumination, Journal of Photochemistry and Photobiology A: Chemistry, 2018, 357, 15, p 72-80. https://doi.org/10.1016/j.jphotochem.2018.02.008

$\mathrm{Fe}_{1 \times} \mathrm{O}=\mathrm{Fe}_{3} \mathrm{O}_{4}, \mathrm{Fe}=\mathrm{Fe}_{1 \times} \mathrm{O}$ thin films prepared by $\mathrm{RF}$ sputtering and revealed by magnetic coupling effects, J. of Magn. and Magnetic Mater., 2008, 320, p 58-62. cleaning methods of glass in preparation for silanisation, Biosensors and Bioelec., 1999,14(8-9), p 683-688.

Photoluminescence and ultraviolet lasing of polycrystalline $\mathrm{ZnO}$ thin films prepared by the oxidation of the metallic Zn, Appl. Phys. Lett., 1999, 75, p 2761 DOI: $10.1063 / 1.125141$

[19] R.P. Wang, G. Xu and P. Jin, Size dependence of electron-phonon coupling in ZnO nanowires, Phys. Rev. B: Condens. Matter.,2004, 69, p 113303-113306.

$$
\text { D. Raoufi, Synthesis and photoluminescence characterisation of } \mathrm{ZnO}
$$
nanoparticles, Journal of luminescence, 2013, 134, p 213-219. grafted ZnO nanoparticles, Powder Technology, 2006, 163(3), 160-168. film deposition parameters on electronic parameters of $\operatorname{In}_{2} \mathrm{~S}_{3} / \mathrm{n}$-InP junctions at various temperatures, J. Alloys Compd. 646 (2015) 954-965. Schneider, Photoluminescence studies on structural defects and room temperature ferromagnetism in Ni and Ni-H doped ZnO nanoparticles, J. Appl. Phys., 2010, 108(2), p 023906. zinc oxide thin films for optoelectronic applications, Heliyon, 2017, 3(4), p e00285 
[25] Fang-Hsing Wang, Chia-Cheng Huang, Cheng-fu Yang, and Hua-Tz Tzeng, Optical and Electrical Properties of the Different Magnetron Sputter Power $300^{\circ} \mathrm{C}$ Deposited $\mathrm{Ga}_{2} \mathrm{O} 3-\mathrm{ZnO}$ Thin Films and Applications in p-i-n $\alpha$-Si: H Thin-Film Solar Cells, Hindawi Publishing Corporation International Journal of Photoenergy, Web, http://dx.doi.org/10.1155/2013/270389, 2013. Accessed 21 February 2013
F. Bouhjar,
B. Marí and
B. Bessaïs, Hydrothermal fabrication and

characterisation of $\mathrm{ZnO} / \mathrm{Fe}_{2} \mathrm{O}_{3}$ heterojunction devices for hydrogen production, J Anal Pharm Res, 2018, 7(3) p 315-321.

BP. Kafle, B. R. Pokhrel and P. Lamichhane, Thickness Dependence of Optical and Electrical Properties of Zinc Oxide Thin Films, SOJ Materials Science \& Engineering, 2013, http://dx.doi.org/10.15226/sojmse.2016.00117. 




Fig. 1 XRD patterns of the $\mathrm{ZnO}$-pure and $\mathrm{Fe}_{2} \mathrm{O}_{3} / \mathrm{ZnO}$ heterostructure thin films.

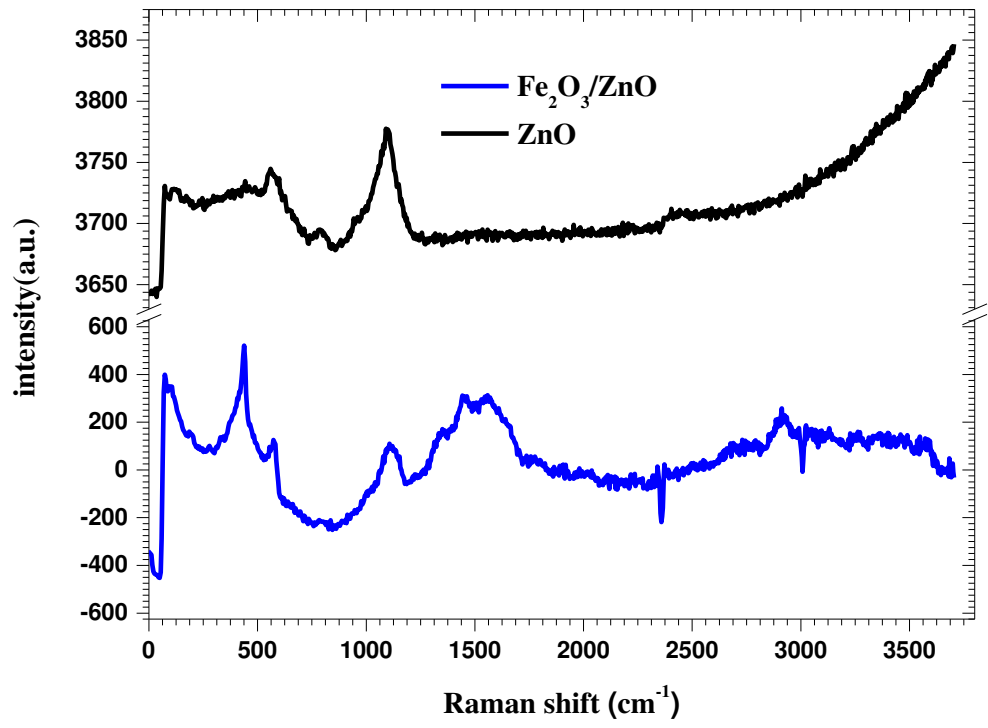

Fig.2 Raman analysis of the $\mathrm{Fe}_{2} \mathrm{O}_{3} / \mathrm{ZnO}$ structure grown on the glass substrate. 


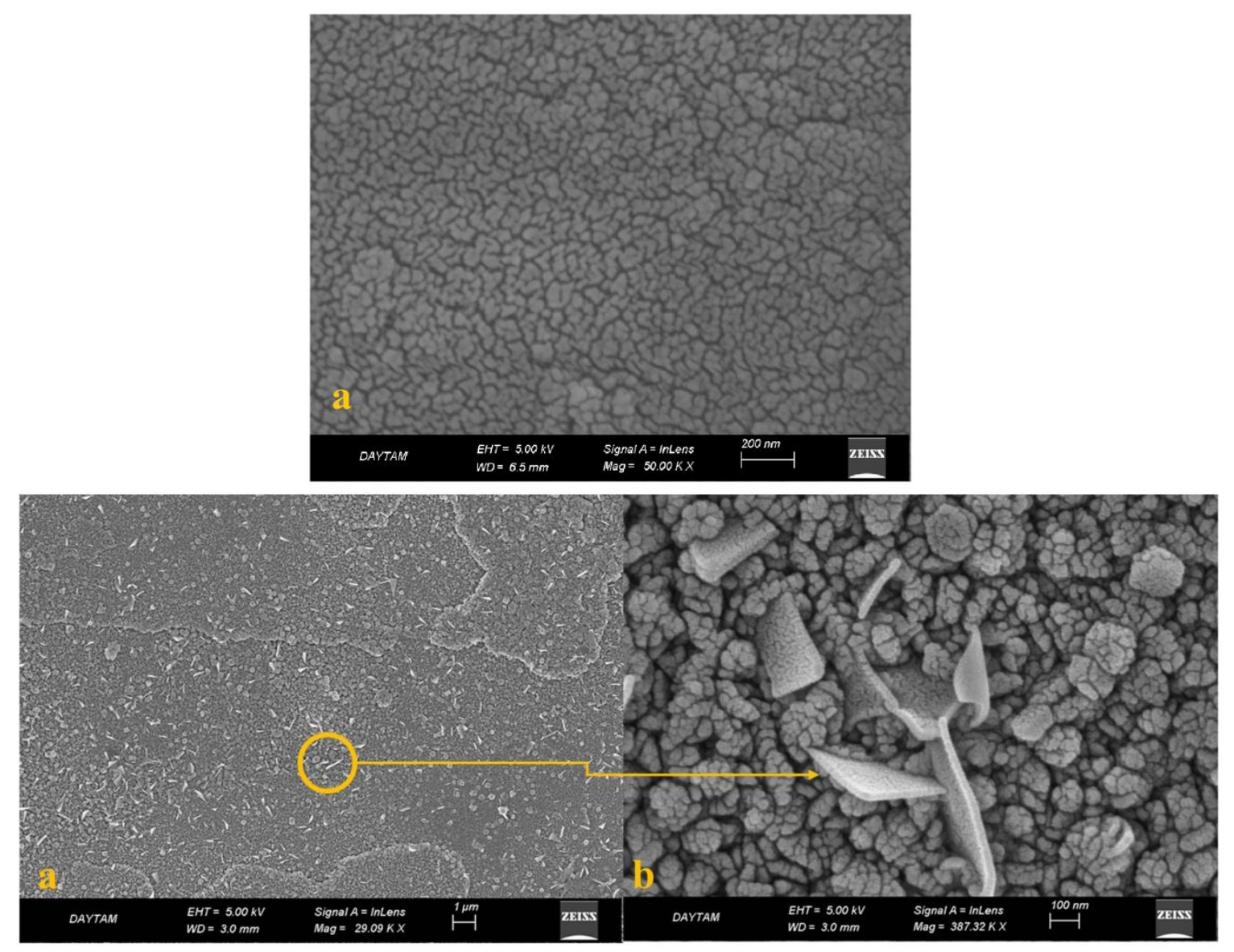

Fig.3 FE-SEM images of (a) $\mathrm{ZnO}$ thin film and $\mathrm{Fe}_{2} \mathrm{O}_{3} / \mathrm{ZnO}$ films with magnification scales, (b) $1 \mu \mathrm{m}$ and (c) $100 \mathrm{~nm}$, respectively.

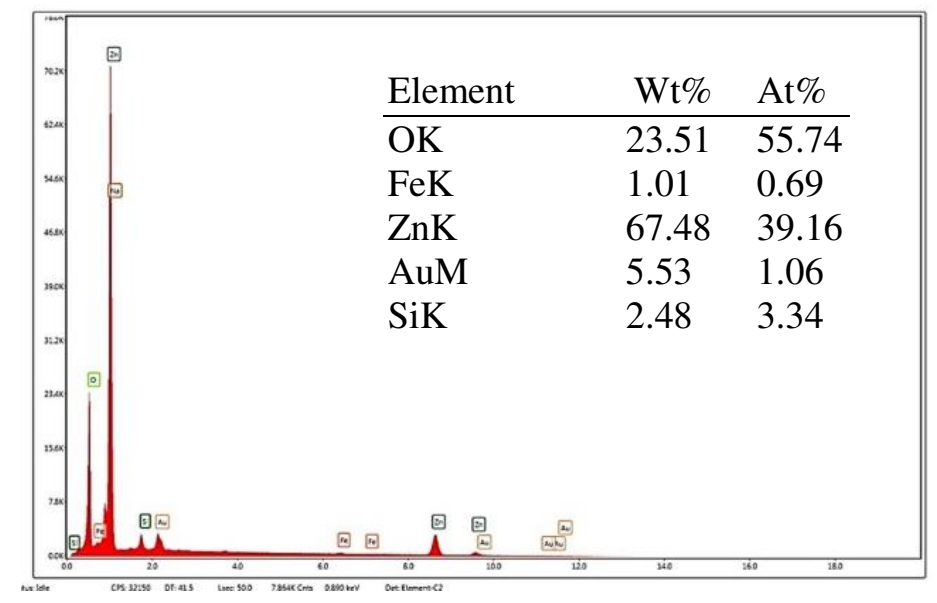

Fig.4 EDX spectrum of the $\mathrm{Fe}_{2} \mathrm{O}_{3} / \mathrm{ZnO}$ structure and the detected $\mathrm{Fe}_{2} \mathrm{O}_{3} / \mathrm{ZnO}$ structure elements with their percentages. 


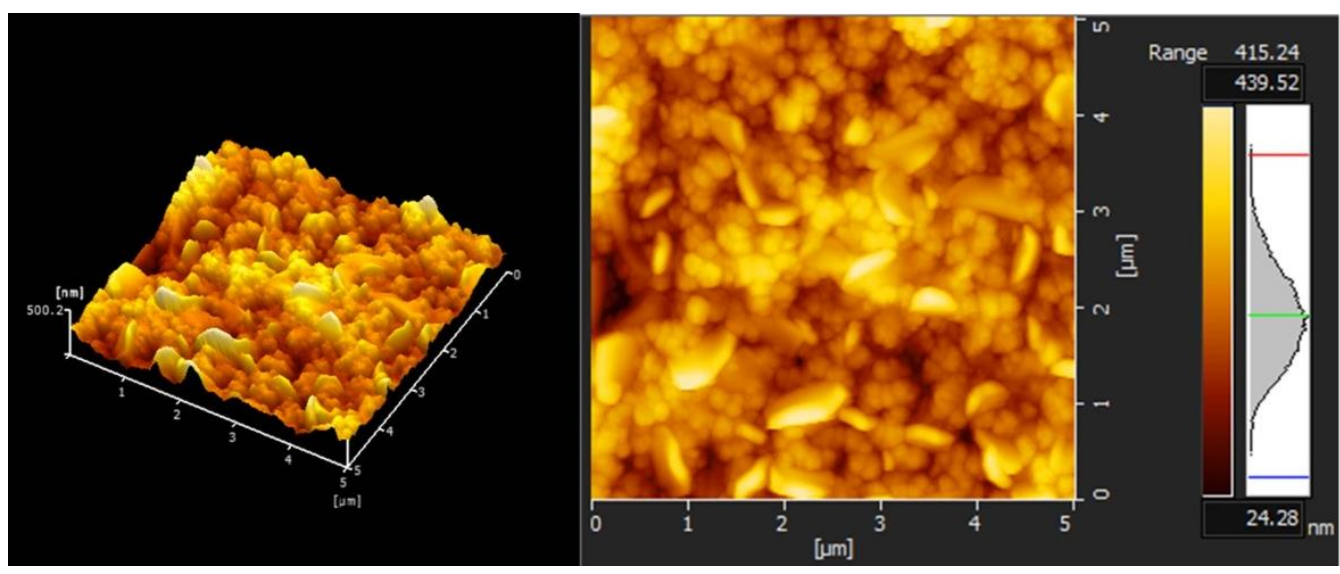

Fig.5 AFM images of the $\mathrm{Fe}_{2} \mathrm{O}_{3} / \mathrm{ZnO}$ structure grown on glass substrates: (a) 3D image $\mathrm{Fe}_{2} \mathrm{O}_{3} / \mathrm{ZnO}$, (b) 2D image (RMS: $459 \mathrm{~nm}$ ).

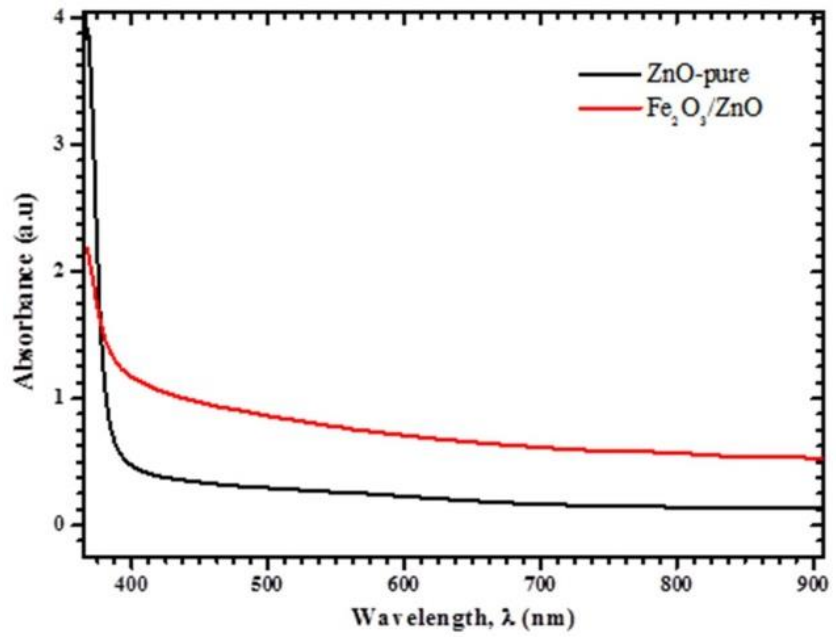

Fig.6 Optical absorbance spectra of the $\mathrm{ZnO}$-pure thin film and $\mathrm{Fe}_{2} \mathrm{O}_{3} / \mathrm{ZnO}$ structure grown on glass substrates versus the wavelength of the incident photon. 


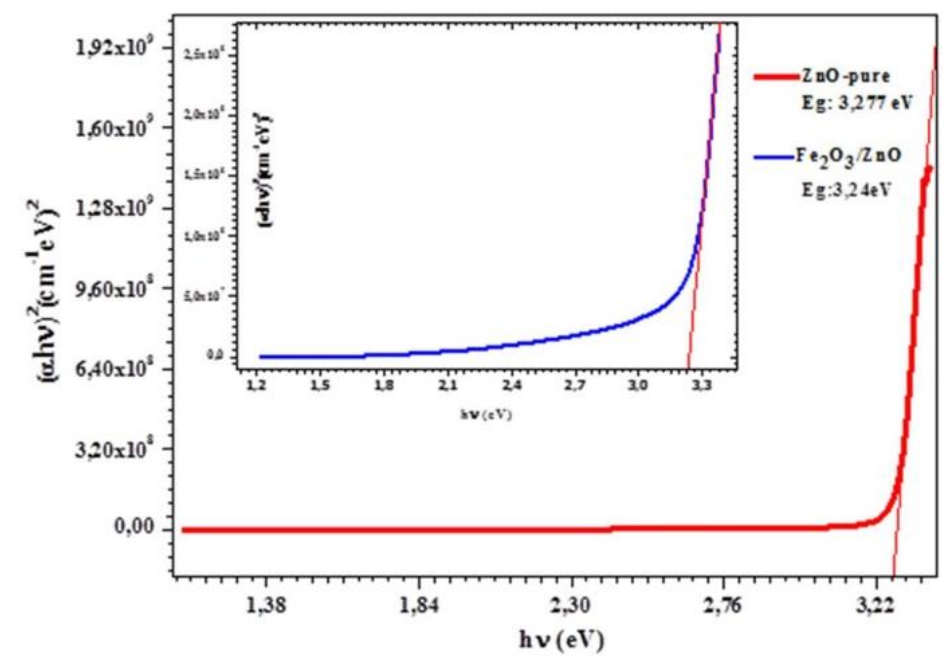

Fig.7 Plots of $(\alpha h v)^{2}$ of $\mathrm{ZnO}$-pure thin film and $\mathrm{Fe}_{2} \mathrm{O}_{3} / \mathrm{ZnO}$ structure grown on the glass substrates versus photon energy (hv).

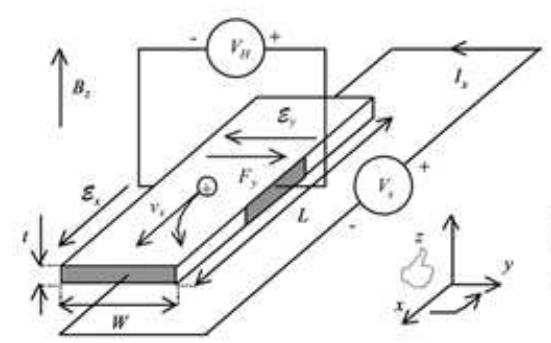

a)

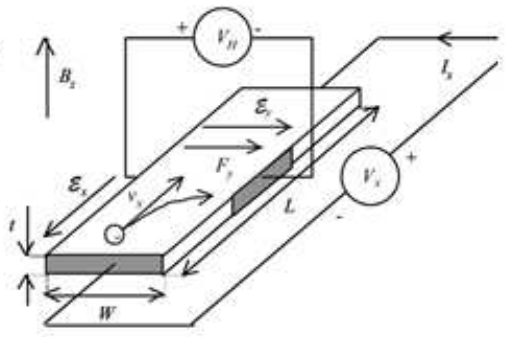

b)

Fig.8 Schematic diagram of Hall experimental set-up presents the carrier motions, for (a) holes and (b) electrons.

\section{FIGURE CAPTIONS}

Fig.1. XRD patterns of the $\mathrm{ZnO}$-pure and $\mathrm{Fe}_{2} \mathrm{O}_{3} / \mathrm{ZnO}$ heterostructure thin films.

Fig.2. Raman analysis of the $\mathrm{Fe}_{2} \mathrm{O}_{3} / \mathrm{ZnO}$ structure grown on the glass substrate.

Fig.3. FE-SEM images of (a) $\mathrm{ZnO}$ thin film and $\mathrm{Fe}_{2} \mathrm{O}_{3} / \mathrm{ZnO}$ films with magnification scales, (b) $1 \mu \mathrm{m}$ and (c) $100 \mathrm{~nm}$, respectively.

Fig.4. EDX spectrum of the $\mathrm{Fe}_{2} \mathrm{O}_{3} / \mathrm{ZnO}$ structure detected the elements in $\mathrm{Fe}_{2} \mathrm{O}_{3} / \mathrm{ZnO}$ structure with their percentages. 
Fig.5. AFM images of the $\mathrm{Fe}_{2} \mathrm{O}_{3} / \mathrm{ZnO}$ structure grown on glass substrates: (a) 3D image $\mathrm{Fe}_{2} \mathrm{O}_{3} / \mathrm{ZnO}$, (b) 2D image (RMS: $459 \mathrm{~nm}$ ).

Fig.6. Optical absorbance spectra of the $\mathrm{ZnO}$-pure thin film and $\mathrm{Fe}_{2} \mathrm{O}_{3} / \mathrm{ZnO}$ structure grown on glass substrates versus the incident photon's wavelength.

Fig.7. Plots of $(\alpha h v)^{2}$ of $\mathrm{ZnO}$-pure thin film and $\mathrm{Fe}_{2} \mathrm{O}_{3} / \mathrm{ZnO}$ structure grown on the glass substrates versus photon energy (hv).

Fig.8. Schematic diagram of Hall experimental set-up presents the carrier motions, for (a) holes and (b) electrons.

Table 1. Crystal structural parameters of $\mathrm{Fe}_{2} \mathrm{O}_{3} / \mathrm{ZnO}$ structure grown on the glass substrate.

\begin{tabular}{|c|c|c|c|c|c|c|}
\hline (hkl) & FWHM (rd.) & $\begin{array}{c}\text { Intensity } \\
\text { (au.) }\end{array}$ & $\begin{array}{c}2 \theta^{\circ} \\
\text { (Observed) }\end{array}$ & $\begin{array}{l}\text { d-values } \\
\text { (nm) }\end{array}$ & $\begin{array}{c}\text { Crystal } \\
\text { size (D) } \\
\text { nm }\end{array}$ & Crystal \\
\hline$(402)$ & 0.00743 & 422 & 32.73 & 0.273 & 18.79 & $\mathrm{Fe}_{2} \mathrm{O}_{3}$ \\
\hline$(040)$ & 0.00764 & 1008 & 35.43 & 0.253 & 20.83 & $\mathrm{Fe}_{2} \mathrm{O}_{3}$ \\
\hline$(200)$ & 0.00767 & 775 & 37.13 & 0.242 & 21.07 & $\mathrm{ZnO}_{2}$ \\
\hline$(102)$ & 0.0082 & 232 & 48.49 & 0.187 & 16.47 & $\mathrm{ZnO}$ \\
\hline$(110)$ & 0.0093 & 202 & 57.56 & 0.160 & 15.41 & $\mathrm{ZnO}$ \\
\hline$(103)$ & 0.0177 & 278 & 63.72 & 0.146 & 13.07 & $\mathrm{ZnO}$ \\
\hline (112) & 0.0098 & 159 & 68.82 & 0.136 & 15.65 & $\mathrm{ZnO}$ \\
\hline$(\mathbf{1 0 0})$ & 0.00813 & 390 & 32.75 & 0.278 & 17.20 & $\mathrm{ZnO}$ \\
\hline$(002)$ & 0.00820 & 812 & 35.54 & 0.258 & 17.13 & $\mathrm{ZnO}$ \\
\hline$(101)$ & 0.00857 & 658 & 37.14 & 0.245 & 16.45 & $\mathrm{ZnO}$ \\
\hline$(402)$ & 0.00743 & 422 & 32.73 & 0.273 & 18.79 & $\mathrm{Fe}_{2} \mathrm{O}_{3}$ \\
\hline
\end{tabular}

Table 2. Measured Hall voltages $\left(\mathbf{V}_{\mathbf{E 0}+}, \mathbf{V}_{\mathbf{E} 1}, \mathbf{V}_{\mathbf{E} 2}\right)$ and $\left(\mathbf{V}_{\mathbf{E} 0-}, \mathbf{V}_{\mathbf{E} 3}, \mathbf{V}_{\mathbf{E} 4}\right)$ of $\mathrm{Fe}_{2} \mathrm{O}_{3} / \mathrm{ZnO}$ structure obtained using four-point probe technique under applied current values $\left(\mathrm{I}= \pm 120^{*} 10^{-6} \mathrm{~A}\right)$ and magnetic field values $(B=0,+2.5$, and $-2.5 \mathrm{~T})$ at $300 \mathrm{~K}$, respectively.

\section{TRANSVERSE MEASUREMENTS}

\begin{tabular}{c|c|c|c|c|c}
\hline \multicolumn{5}{c}{ Voltage Values $(V)$} \\
\hline$V_{\text {E0+ }}$ & $V_{\text {E1 }}$ & $V_{\text {E2 }}$ & $V_{\text {E0- }}$ & $V_{\text {E3 }}$ & $V_{\text {E4 }}$ \\
\hline $\mathbf{0 , 4 5 6 2 8 1}$ & $\mathbf{0 , 4 5 5 9 5 7}$ & $\mathbf{0 , 4 5 5 2 9 7}$ & $\mathbf{- 0 , 4 4 2 1 6 8}$ & $\mathbf{- 0 , 4 5 6 0 5 1}$ & $\mathbf{- 0 , 4 5 0 3 2 2}$ \\
\hline
\end{tabular}


Figures

Fig.1

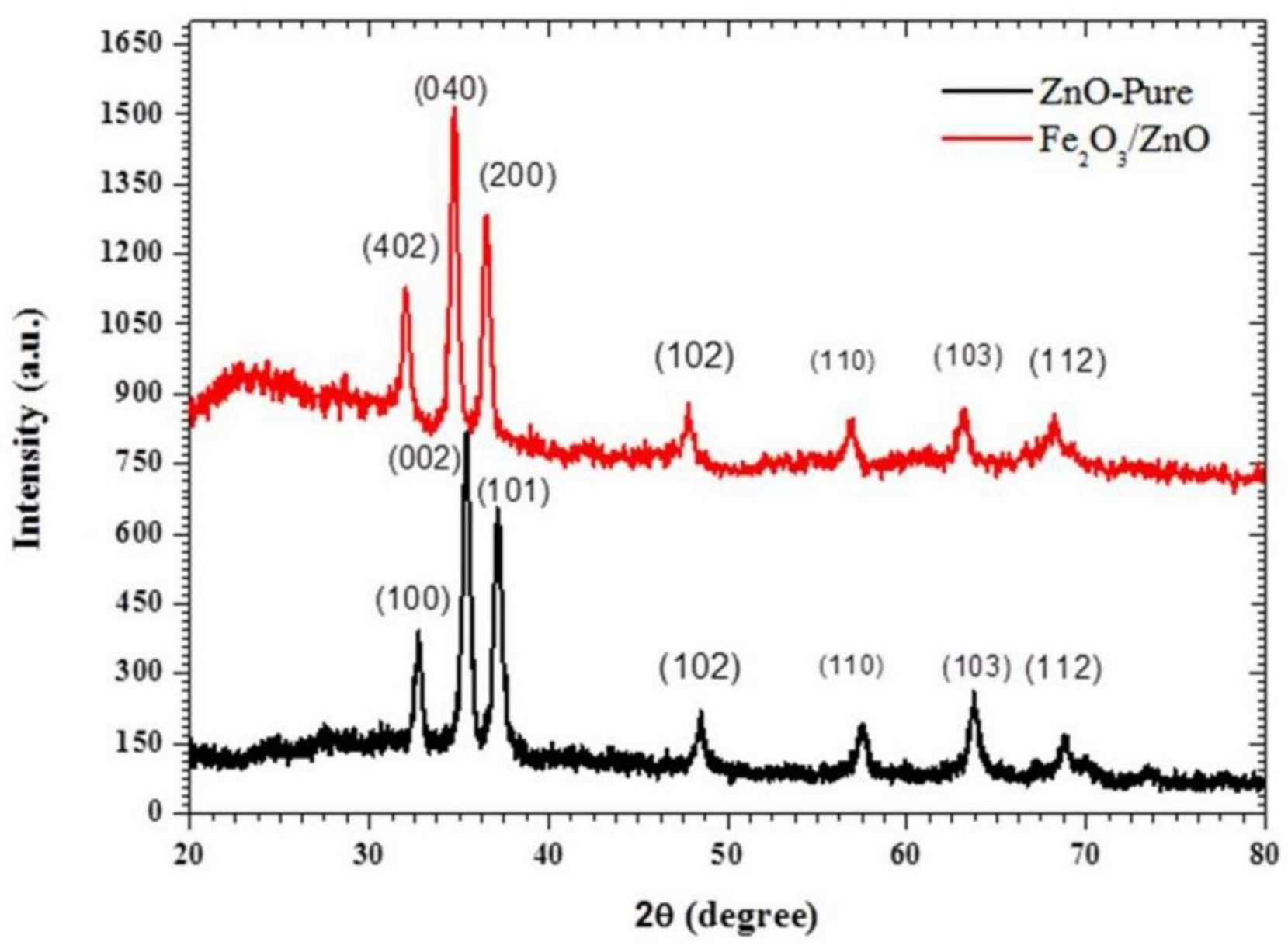

Figure 1

XRD patterns of the ZnO-pure and Fe2O3/ZnO heterostructure thin films. 
Fig. 2

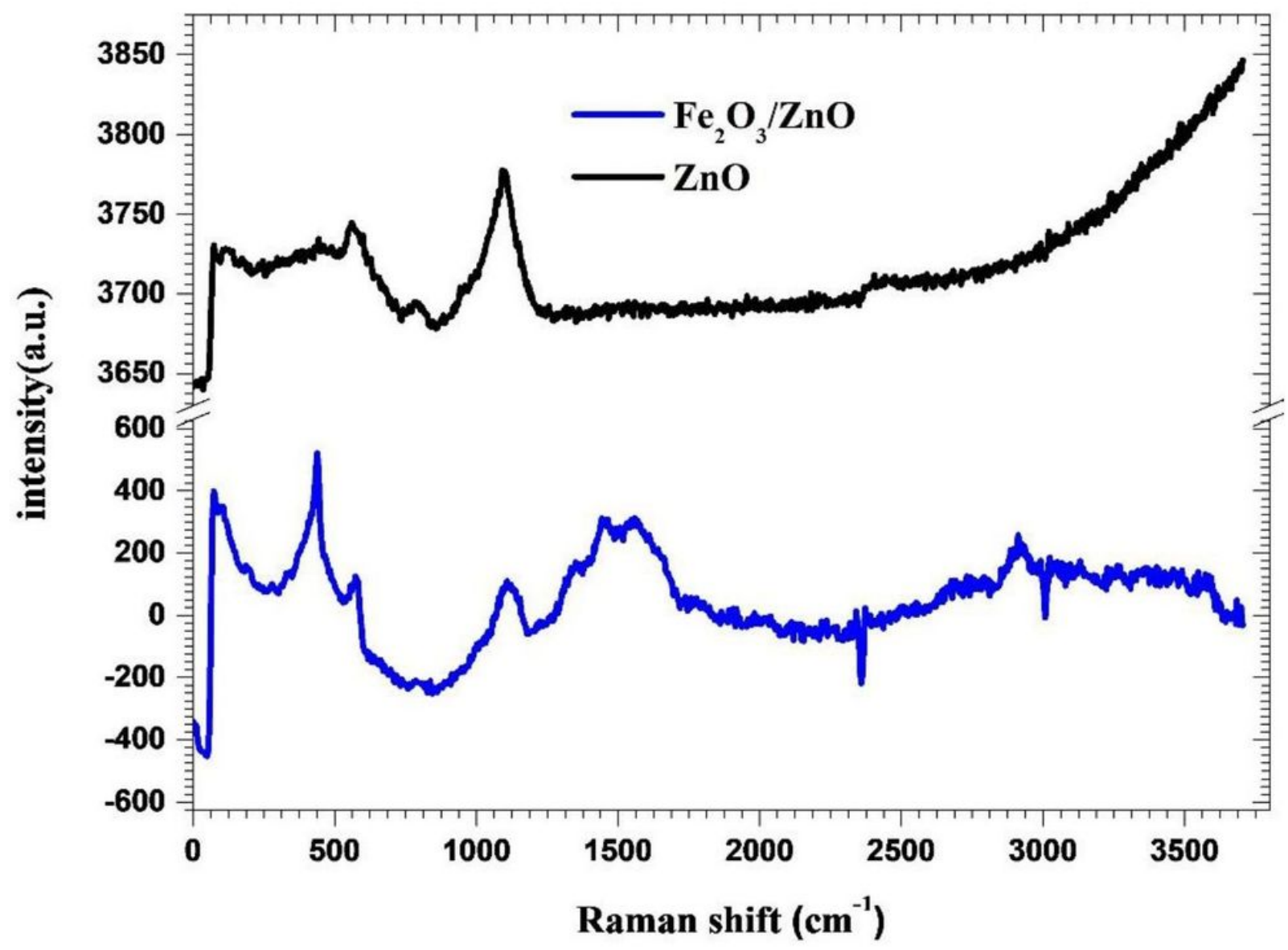

Figure 2

Raman analysis of the Fe203/ZnO structure grown on the glass substrate. 
Fig. 3
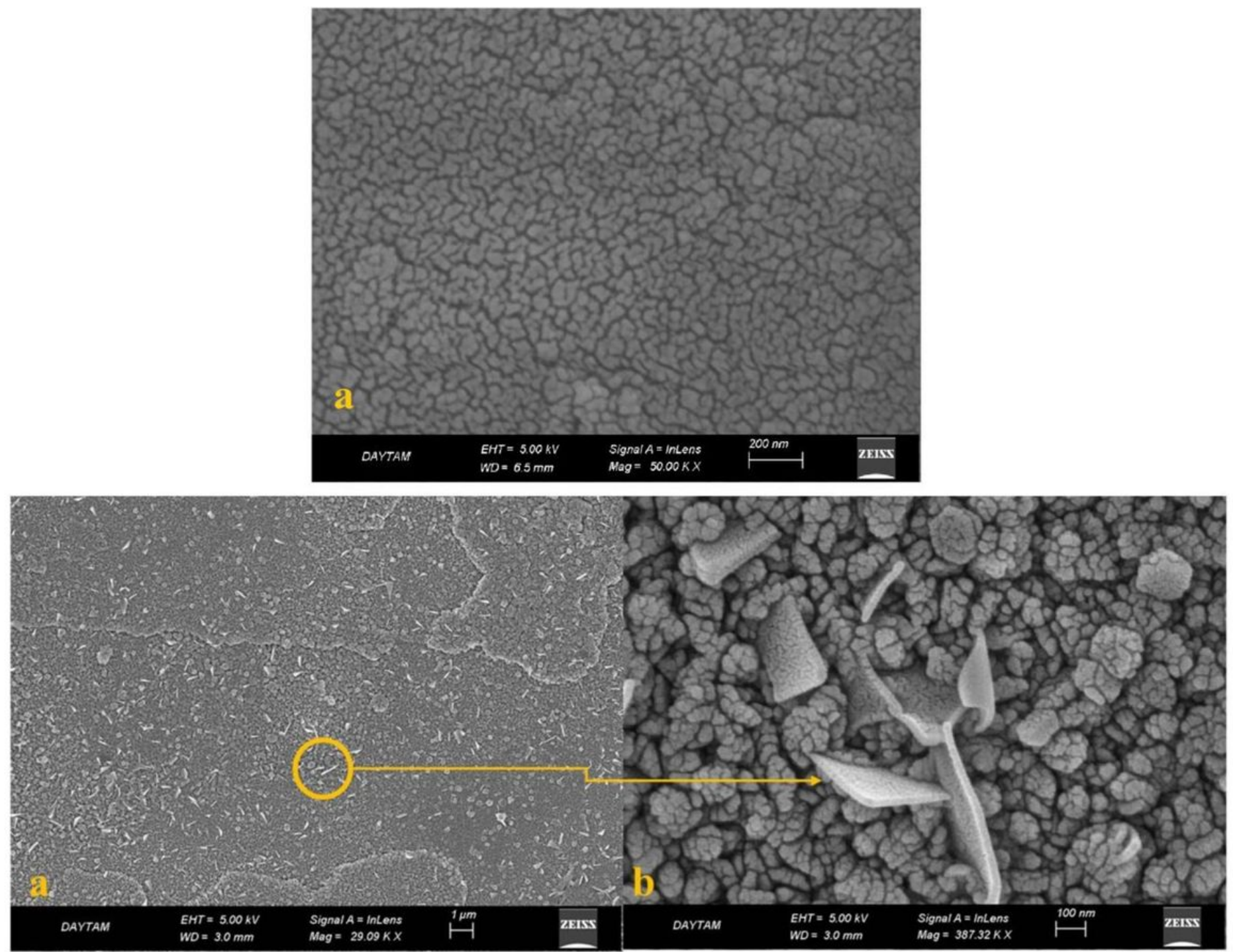

Figure 3

FE-SEM images of (a) ZnO thin film and Fe2O3/ZnO films with magnification scales, (b) $1 \mu \mathrm{m}$ and (c) 100 $\mathrm{nm}$, respectively. 
Fig.4

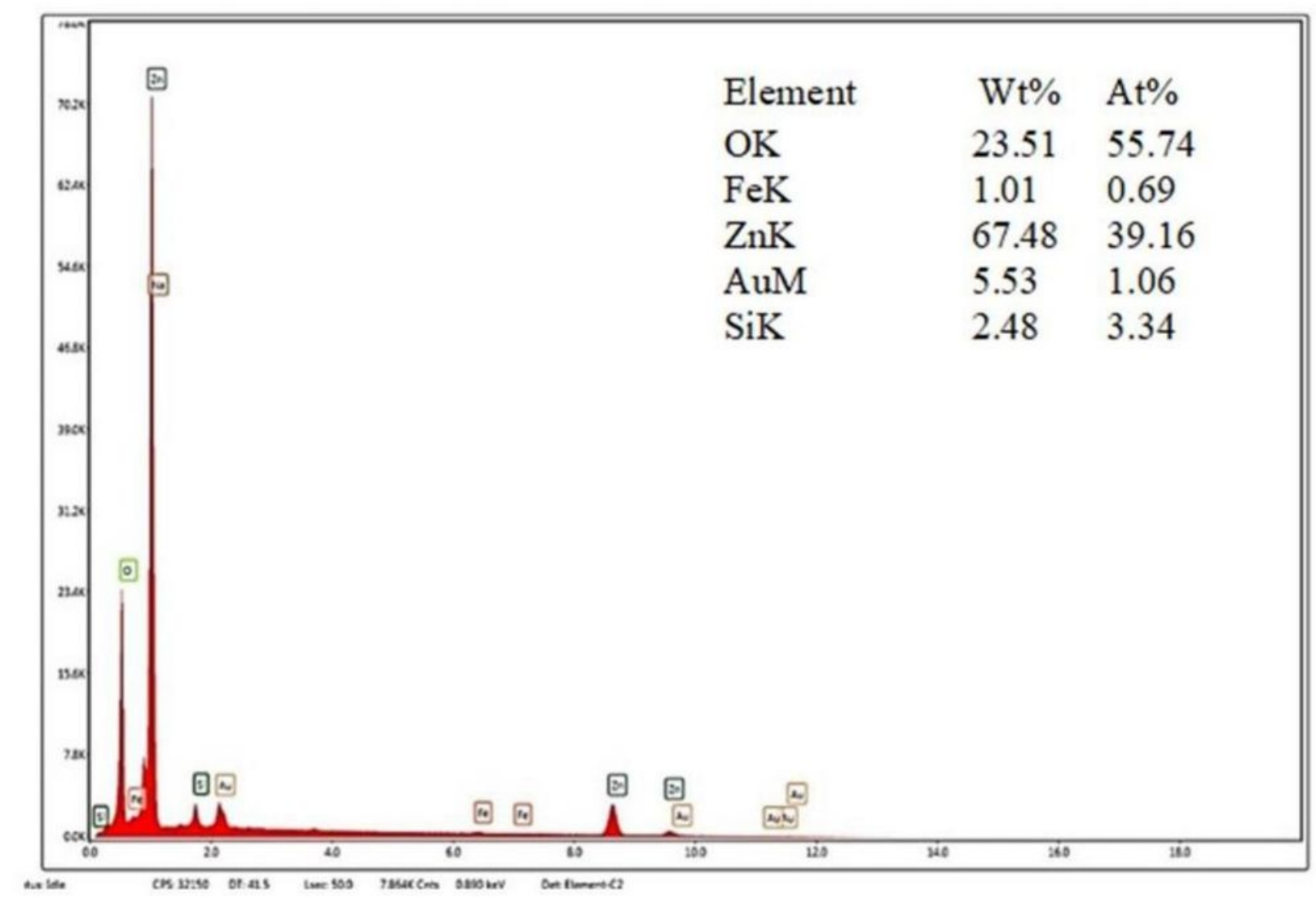

Figure 4

EDX spectrum of the Fe2O3/ZnO structure detected the elements in Fe2O3/ZnO structure with their percentages. 


\section{Fig.5}

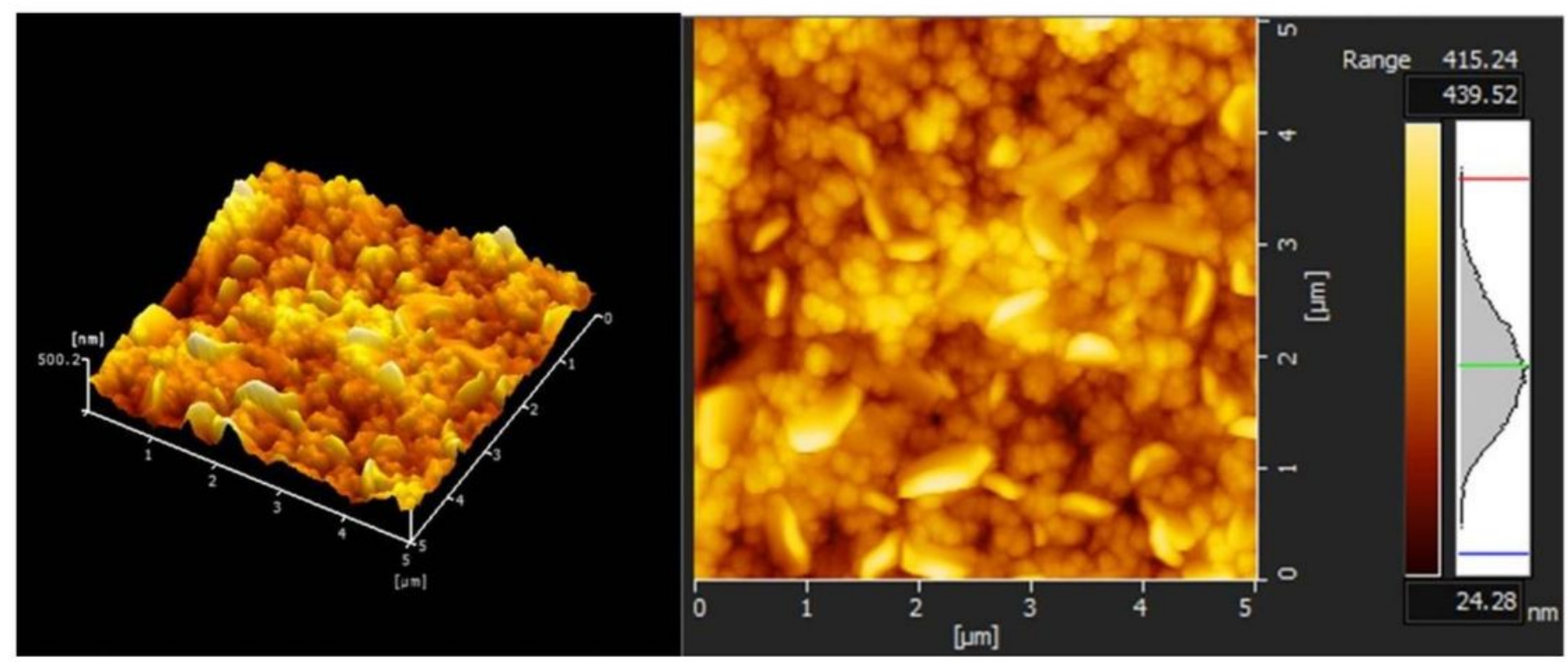

\section{Figure 5}

AFM images of the Fe203/ZnO structure grown on glass substrates: (a) 3D image Fe203/ZnO, (b) 2D image (RMS: $459 \mathrm{~nm}$ ). 
Fig.6

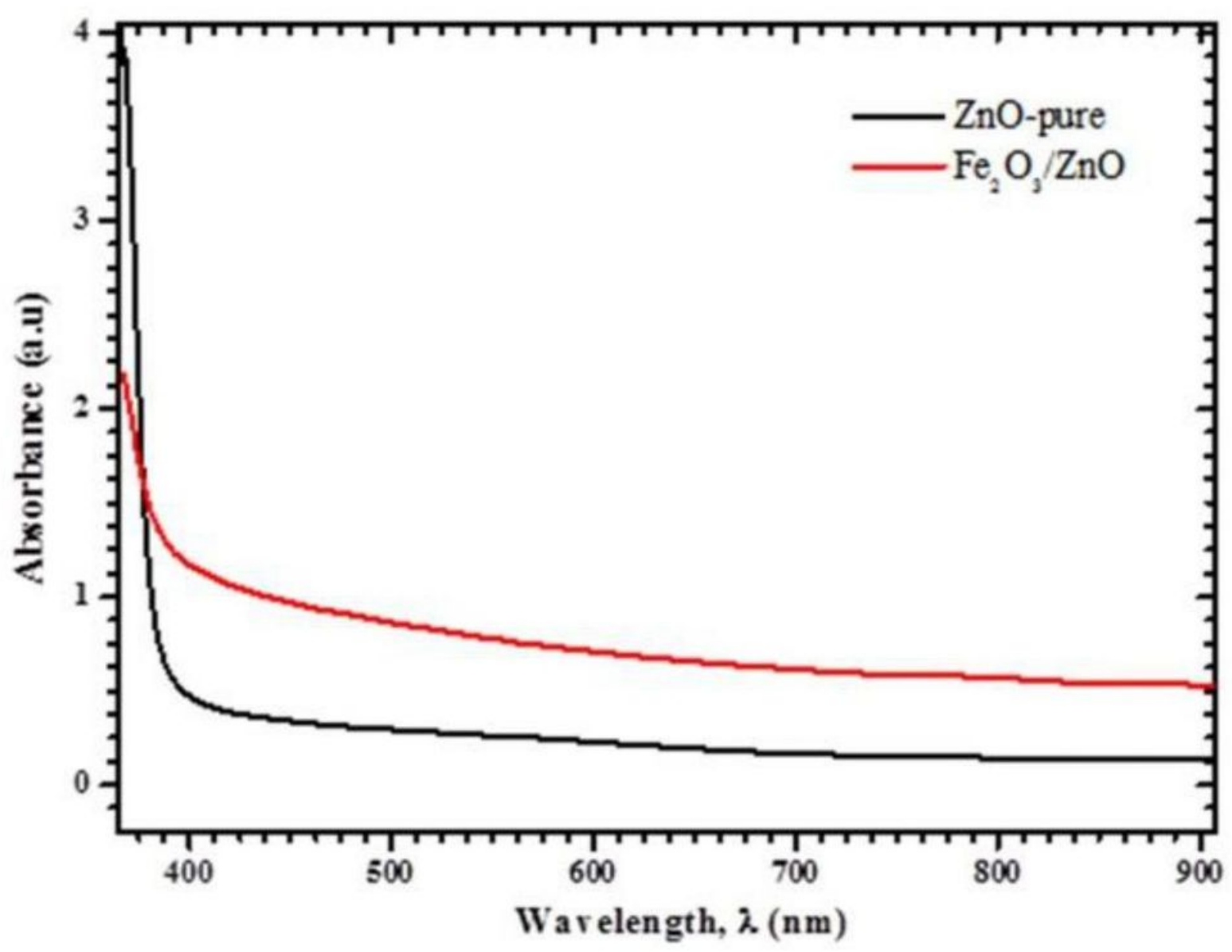

Figure 6

Optical absorbance spectra of the ZnO-pure thin film and Fe203/ZnO structure grown on glass substrates versus the incident photon's wavelength. 
Fig. 7

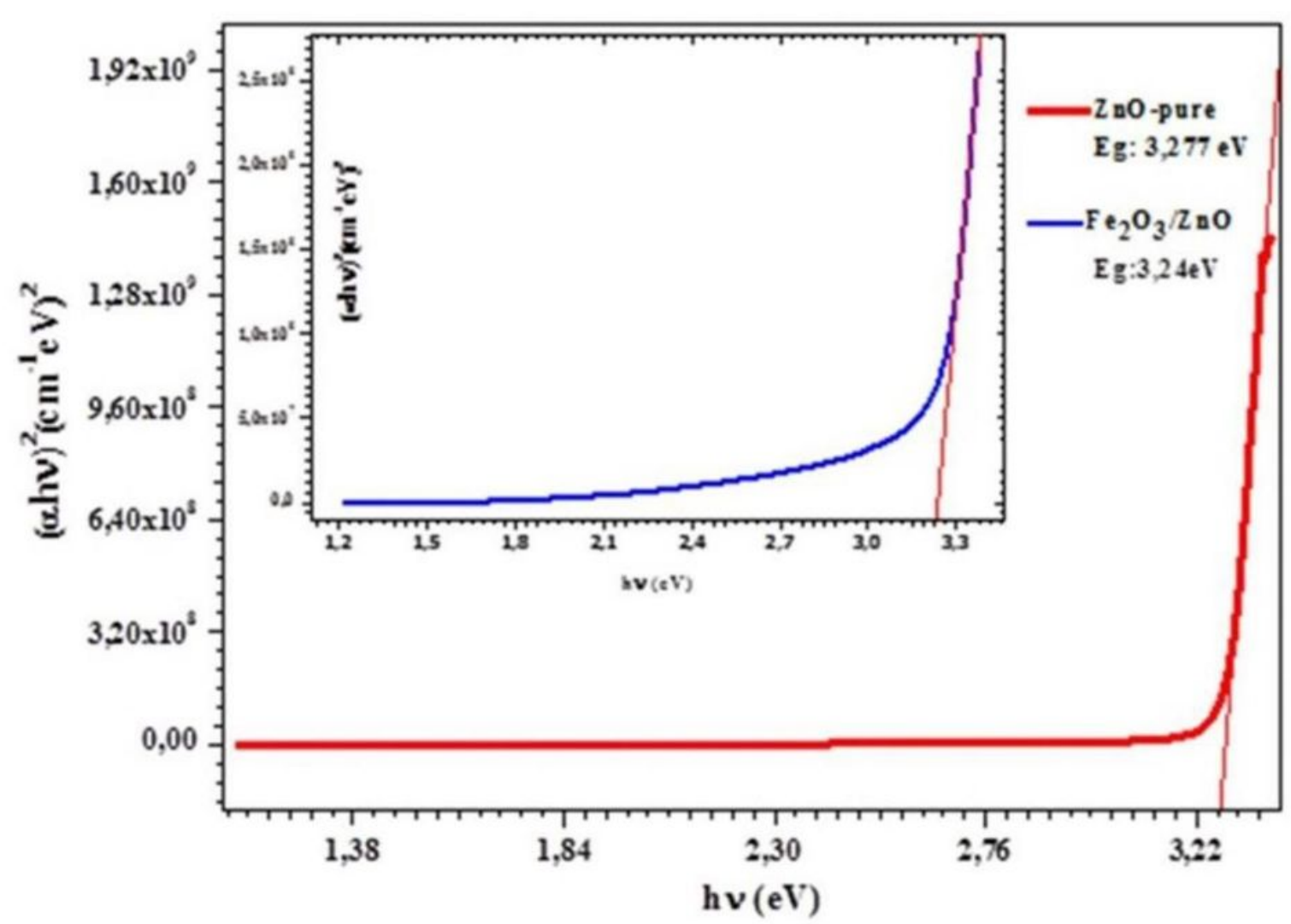

Figure 7

Plots of (ahu) 2 of ZnO-pure thin film and Fe2O3/ZnO structure grown on the glass substrates versus photon energy (hu). 
Fig. 8
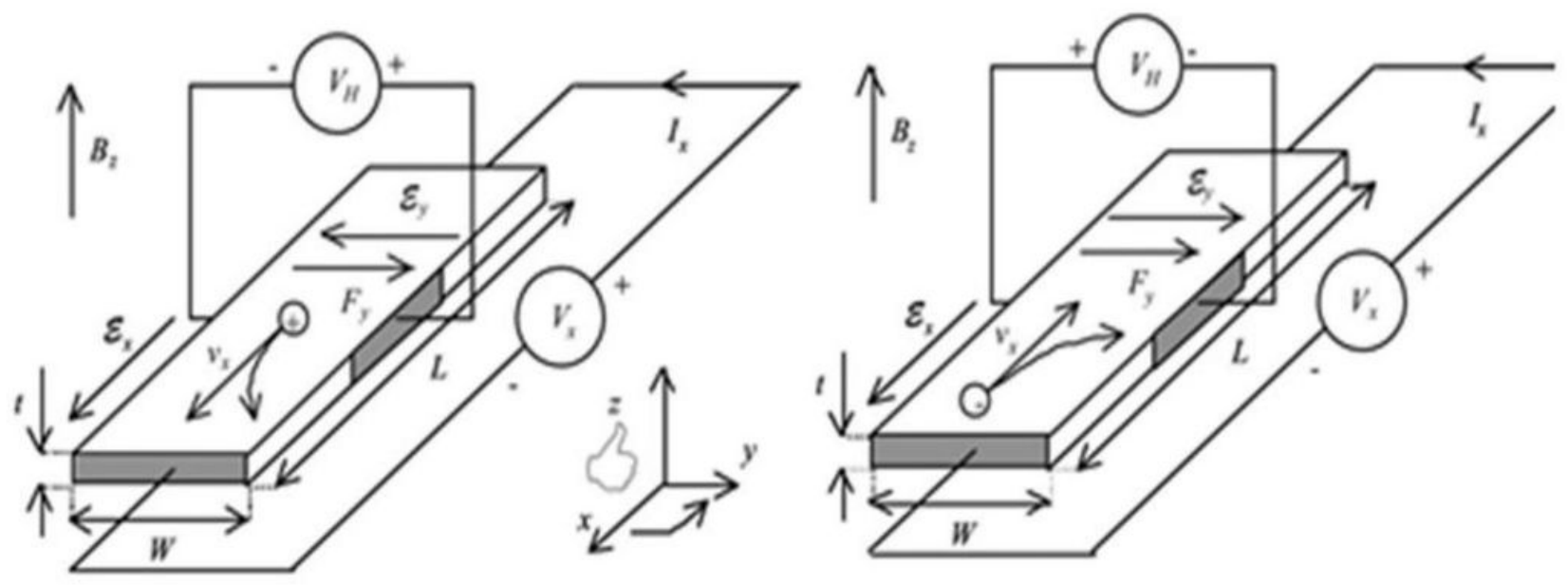

a)

b)

Figure 8

Schematic diagram of Hall experimental set-up presents the carrier motions, for (a) holes and (b) electrons. 